\title{
RSP Revisitada O Estado, a administração e os serviços públicos no mundo democrático
}

\author{
Themistocles B. Cavalcanti \\ Procurador da República no Distrito Federal \\ (Conferência realizada em 29 de setembro de 1943, na Academia Brasileira de Letras, por \\ iniciativa do P.E.N. Clube do Brasil)
}

Texto publicado na RSP, vol. IV, n² 2, de novembro de 1943

No pleito de 2010, por meio do exercício do direito ao voto, os brasileiros escolhem importantes cargos eletivos, inclusive o de presidente da República. Com isso, o Brasil que, como outros países da América Latina, vivenciou anos de ditadura e ingressou tardiamente na marcha para a democracia, segue consolidando a sua posição.

Nesse contexto, a RSP Revisitada retoma discurso do ano de 1943, proferido em conferência na Academia Brasileira de Letras, por Themístocles Brandão Cavalcanti, ocupante de inúmeros cargos públicos. Em sua fala, trata de temas como: paz, democracia, direito e igualdade política, pontuando o papel do Estado, da administração e dos serviços públicos no enfrentamento desses e outros desafios.

Para Themístocles, o Estado - com o seu aparato - deve ser capaz de assumir, em toda a sua plenitude, os encargos decorrentes de sua conceituação democrática, resguardando direitos individuais, liberdades públicas e interesses justos e legítimos. Deve também prestar serviços públicos de qualidade e atender às demandas essenciais da coletividade; assegurando, assim, a identificação dos fins do Estado com os fins do Homem, e não dos fins do homem com os fins do Estado.

Os problemas da Paz serão, um dia, debatidos, agitados e resolvidos nas Conferências internacionais, entre os construtores do mundo democrático de amanhã, homens de trabalho, homens de ciência, homens de política.

Aí, os economistas discutirão as medidas para o reajustamento econômico do mundo; os financistas, as soluções para o equilíbrio monetário; os médicos, suas conclusões para a recuperação física de homens, mulheres e crianças 
semi-devoradas pela guerra; os juristas, as formas de equilíbrio social; os políticos, os seus projetos para construção de novos Estados sôbre bases livres e democráticas.

Dessa mesa, serão negados os perturbadores da paz social, os que provocaram as crises políticas e as lutas econômicas, os exploradores dos monopólios, os que, sob o pretexto de defenderem a democracia e a paz, com elas e seus princípios negociaram.

As soluções serão completas e conclusivas, frutos da experiência, dos debates e estudos doutrinários, cuja única virtude não está, sòmente, na agitação dos espíritos e no seu preparo para a tragédia da Paz que se aproxima.

Para essa agitação e êsse preparo, temos estado nós aqui, nesta sala acolhedora da Casa de Machado de Assis, afugentando por algumas horas as Musas, para tratarmos de assuntos políticos, sociais, econômicos, que, numa coincidência dos nossos sentimentos comuns, visam estabelecer, no mundo, não pròpriamente o domínio das Utopias, mas uma espiritualidade que possa elevar os homens de amanhã a desígnios mais altos.

Se as resoluções definitivas da grande mesa da Paz sòmente se conhecerão quando silenciarem os canhões, quando a liberdade sair da penumbra em que vive e não sofrer mais as limitações da guerra, quando o Homem recuperar a posse de si mesmo, - até lá, não será demasiado debater os diversos problemas que atingem e preocupam a cada um de nós, e cuja solução possa concorrer para a manutenção da Paz.

Tema desta palestra é o problema do Estado e da Administração perante o pensamento democrático.

Alexis de Tocqueville, o grande democrata francês, tão ligado ao continente americano, escreveu há um século - que a marcha para a Democracia era o fato mais constante, mais acentuado e mais irresistível da História.

$\mathrm{E}$ demonstrou que esse movimento cada vez mais se afirma por um nivelamento progressivo de todos os homens, na esfera política, na esfera social e na esfera econômica.

A experiência da evolução política do século XIX para cá veio, apenas, demonstrar a segurança daqueles conceitos, isto é, de que o princípio da simples igualdade política é, apenas, o início das transformações dos regimes para a Democracia, não obstante as reações verificadas contra essa evolução.

Mas tais reações devem ser consideradas como crises naturais, - de crescimento da idéia democrática, e da insuficiência do pensamento político para conter, em toda a sua plenitude, os problemas complexos da Democracia.

O Estado democrático é, em sua formação histórica, o resultado de um processo de identificação do povo com o Estado, já pela sua participação mais direta nos órgãos do Govêrno, já, e em conseqüência, na conquista de novas liberdades humanas, liberdades que não podem medrar nem ser obtidas sob Governos absolutos.

Essa integração do Estado com o Indivíduo, essa identificação do homem com a coletividade é, talvez, um dos aspectos mais característicos da evolução do regime, evolução cujos perigos não têm sido bem compreendidos por uma certa corrente conservadora, que, ao aplaudir os seus sucessos, não se apercebe sempre bem das conseqüências fatais e irresistíveis do desenvolvimento da idéia democrática.

Observou, por isso, Rodolfo LuAn, referindo-se aos conservadores mais 
atilados, que a luta contra o pretenso individualismo da democracia é apenas uma reação burguesa daqueles que compreendem o sentido da marcha da democracia para o socialismo -, pontos em que as duas doutrinas se identificarão e cristalizarão.

É preciso, entretanto, advertir que, embora existam afinidades ontológicas e finalísticas entre os dois sistemas, a sua construção futura e os seus fundamentos dependerão dos fatores éticos e econômicos que influírem e participarem mais diretamente no desenvolvimento dessas ideologias.

$\mathrm{E}$ os fatores morais e religiosos deverão ter, nas modificações sociais, influência tanto maior e tanto mais profunda, quanto maior e mais profunda se tornar essa transformação.

Ora, se a democracia é um processo de nivelamento de direitos, pela aplicação exata do conceito da igualdade; se a finalidade da democracia é integrar o direito de cada um no direito de todos; se a democracia deve identificar o Estado com o interêsse de todos os indivíduos, - surge, desde logo, como um dos mais sérios obstáculos à plena execução do sistema democrático, o problema do govêrno de todos pela maioria.

Porque o regime das maiorias pressupõe a dominação de alguns, a subordinação ao número, a predominância de grupos e partidos, a sujeição das minorias, a desigualdade de fato.

O equilíbrio político perfeito nem sempre é possível dentro dos quadros restritos dos poderes constitucionais. Pressupõe, na observação feliz de Guglielmo Ferrero, - uma compreensão mútua das posições recíprocas do Govêrno e da Oposição, que sòmente pode existir nos povos de cultura política avançadíssima, ou melhor, em estados muito adiantados da evolução democrática, raramente encontrados, mesmo nos povos já civilizados.

Daí o concluir-se que, embora seja a forma representativa de Govêrno da essência das instituïções democráticas, a crítica tem, entretanto, demonstrado não ser suficiente, apenas, a aplicação do sistema representativo na construção dos órgãos políticos, para caracterizar o regime.

Não há uma concepção unívoca da democracia, desdobrando-se o seu conceito em tantos outros quantas são as formas essenciais de suas manifestações: Democracia política - Democracia social - Democracia econômica.

Se o govêrno das maiorias é um imperativo da Democracia política, na organização do Estado existe um aparelhamento onde não podem prevalecer as maiorias, aparelhamento que deve ser a afirmação constante de uma participação popular extensiva e direta, onde o sistema do voto é proscrito, onde vigora o regime da igualdade jurídica e do mérito individual.

É a Administração, - largo campo de contacto entre o Govêrno e governados, instrumento da Democracia, destinado a aplainar as deformações, os excessos dos órgãos políticos. Constante da organização do Estado na perpétua mutuação dos seus órgãos representativos.

Sistema nervoso da organização estatal, como já foi denominada, é pela Administração que se estabelece o contacto permanente do Govêrno com o povo na sua rotina diária, nas diversas manifestações de polícia, desde o tráfego urbano, a higiene pública, a Assistência, os transportes, o fisco, os serviços públicos de uso elementar da vida quotidiana, até às intervenções mais transcendentes com a segurança nacional e internacional, e a Justiça.

Mas, para que a Administração seja, realmente, um instrumento da Democracia, 
deve a constituïção dos seus órgãos ter uma origem eminentemente democrática, origem fixada nas diversas Declarações de Direitos e consagrada em todas as nossas Constituïções republicanas:

"Todos são iguais perante a Lei.

Os cargos públicos são acessiveis a todos, salvo as condições de capacidade prescritas nas leis e regulamentos".

E essa origem democrática é tanto mais necessária, quando se considera que, através da Administração, é que se torna efetiva a intervenção do Estado nas atividades individuais.

É ainda através dos órgãos da Administração que o Estado exerce uma das suas funções mais importantes: - a execução dos serviços públicos.

Não cabe, aquí, desenvolver aspectos eminentemente técnicos dêste problema. Cabe, entretanto, pôr em relêvo as condições elementares a que deve obedecer o exercício dessa função no regime democrático.

Serviço Público significa - atender aos interêsses essenciais da coletividade, pôr à disposição de todos, as utilidades exigidas pelo Homem civilizado, como indispensáveis à vida. É a expressão mais viva do Govêrno "para o Povo".

Serviço Público quer dizer - serviço ao alcance do público.

Quando se fala em prover às necessidades elementares da vida, entende-se, naturalmente, que estas sejam fornecidas atendendo à capacidade aquisitiva dos usuários, dos consumidores.

Sem esta eqüivalência, não há Democracia nem justiça social.

E a responsabilidade do Estado não é menor, quando delega a particulares a exploração dêsses serviços.

É êle o fiador do concessionário perante o público, quer quanto à quantidade, à qualidade, e ao preço do serviço, porque o consumidor não intervém na relação jurídica senão através dos órgãos estatais.

Cabe-lhe, portanto, estabelecer um regime jurídico que seja, efetivamente, o justo equilíbrio dos interêsses em jôgo.

É esta a função precípua do Estado democrático, em relação aos Serviços Públicos.

Mas, para atingir a êsses objetivos, quer nas intervenções do Estado nos serviços públicos, quer nas atividades individuais a Administração, em seu sentido democrático, não pode ser uma organização fechada. Ela deve, também, alicerçar os seus processos, os seus métodos, a sua política, a sua técnica, na experiência, nos pareceres e nos estudos das instituïções científicas de iniciativa privada.

Essa participação ativa dos homens de saber, das organizações científicas e culturais, como verdadeiro prolongamento da atividade estatal, essa participação de toda a coletividade na vida pública, - deve constituir um meio de atingir o ideal democrático, ideal nem sempre totalmente alcançado pelo simples exercício do direito de voto ou pela ação de parlamentos, que são, por vezes, meras expressões formais da Democracia.

É preciso demolir certas barreiras que separam, ainda, o povo da Administração, evitar o "tabú" da ciência oficial e os monopólios científicos de certos grupos, organizar um regime de responsabilidade efetiva e de uma ampla colaboração no sentido de melhorar as condições atuais do Homem.

À administração pública, articulada com as atividades e iniciativas particulares, é que deve caber essa tarefa.

O Estado, mesmo antes da guerra, já delineou os têrmos dêsse entendimento entre os órgãos administrativos e as instituïções privadas. 
A criação de conselhos técnicos, a convocação dos homens de experiência mesmo sem a sua incorporação aos quadros do funcionalismo, uma planificação orientada por uma sábia previsão dos acontecimentos, articulando, coordenando e harmonizando todas as atividades no interêsse coletivo, já constituíam, antes da guerra, instrumentos técnicos da Democracia.

Essa colaboração, que importa numa verdadeira descentralização dos serviços e das instituïções puramente estatais, evitará outros problemas da maior gravidade: a hipertrofia dos órgãos administrativos, a burocratização intensiva, o govêrno dos técnicos, enfim a chamada Tecnocracia.

Esses males, a nosso ver, podem, ain$\mathrm{da}$, ser amenizados por uma conveniente dosagem do critério burocrático com o sentido político dos problemas, e com uma bem compreendida influência científica.

A política, pelos seus órgãos próprios, servirá para suprimir as asperezas da rotina, os perigos de uma burocratização excessiva, das soluções terra-a-terra, dos critérios padronizados e dos entusiasmos precoces de uma ciência em formação.

Servirá o pensamento político para dirigir, para orientar, para animar e humanizar a administração, fornecendo-lhe as suas diretrizes mestras, reagindo contra a algidez de uma tecnocracia, cujos efeitos e exageros só podem ser prejudiciais à própria administração.

Servirá para uma insistente lembrança dos direitos individuais, das liberdades públicas, dos interêsses justos e legítimos a serem protegidos.

Servirá para amenizar os efeitos de uma planificação exagerada, naquilo que esta possa tirar ao indivíduo, das suas qualidades pessoais, dos benefícios da iniciativa individual, das exigências fundamentais da liberdade.

Por outro lado, a aplicação dos métodos científicos, perdendo o caráter de privilégio e monopólio de um grupo, para se consubstanciar na colaboração livre dos cientistas, fora dos moldes da intervenção puramente burocrática, ou interessada, será um meio eficaz para a melhoria das condições gerais da administração.

Já em 1941, uma sugestão neste sentido era apresentada, em Londres, pelo Prof. A. V. HiLl, um dos detentores do prêmio Nobel. E, numa das conferências pelo Progresso da Ciência, realizadas naquela capital, foi observado que: a Ciência e o Bem Estar humano devem ser inseparáveis para não sossobrarem na tragédia dos dias atuais.

Esta participação da Ciência, para o bem estar comum na administração pública, constitue um dos problemas mais fascinantes da atualidade, e a sua solução parece orientar-se no sentido de uma colaboração livre, mas intensa, especialmente nos setores da instrução, dos serviços sociais, da assistência à saúde, da previdência em todas as suas aplicações .

Os métodos científicos têm a virtude de tornar impessoais as soluções, substituem, de alguma forma, o arbítrio por critérios objetivos, aumentam o rendimento da organização burocrática, tornando, assim, mais eficiente o Serviço Público.

Tudo isto permite à Administração pública nivelar-se às emprêsas particulares, quanto aos seus processos, fazendo desaparecer a lenda criada por certas escolas econômicas e políticas, - da incapacidade do Estado para exercer certas funções, que consideram privativas $\mathrm{da}$ iniciativa particular.

O Estado democrático, pela sua estrutura, pela forma de nomeação dos seus servidores, pelo espírito que deve animar 
os serviços públicos, estará, então, em condições de assumir, em toda a sua plenitude, os encargos decorrentes da sua conceituação democrática.

De todas estas considerações, podemos concluir:

1. ${ }^{\circ}$ Que a forma política representativa, característica da Democracia é, apenas, um dos meios de atingir o ideal democrático.

2. ${ }^{\circ}$ Que ainda se impõe, na organização do Estado, uma participação intensiva e extensiva do povo, na sua estrutura administrativa.

3. ${ }^{\circ}$ Que uma ampla colaboração das instituïções privadas com a administração constitue, também, um meio para um melhor entendimento do povo com os seus dirigentes e, portanto, para a formação de um ambiente democrático.

4. ${ }^{\circ}$ Que os serviços públicos, pela sua eficiência, pelos seus métodos e pelos seus fins, sejam realmente a expressão de um govêrno "para o Povo".

5. Q Que, sendo assim, deve o Estado prover à satisfação de todas as utilidades essenciais à vida, ao nível da civilização atual e em condições acessíveis à generalidade da população.

6. Que todos os homens devem possuir, como reivindicação mínima, para uma paz democrática, - direito à subsistência, ao teto, à liberdade.

As formas políticas representativas são simples instrumentos da democracia para o bem comum. Servem, também, para satisfazer os velhos apetites políticos, que já Aristóteles considerava um dos atributos inerentes ao homem.

O essencial é que a forma política resguarde a liberdade, em todas as suas manifestações, suprima a violência, o arbítrio, a opressão sob todos os seus aspectos, a dominação do mais pobre pelo mais rico, do mais fraco pelo mais forte, do homem de côr pelo homem branco. Assegure a todos: teto, saúde, trabalho, amparo físico, material e espiritual.

Que não se veja mais o espetáculo deprimente para a civilização cristã, de milhares de homens sem trabalho, sem pão, sem liberdade.

Esta é a Democracia de que o mundo necessita.

Esta é a Democracia que a máquina estatal deve assegurar, pela identificação dos fins do Estado com os fins do Homem, e não, na fórmula totalitária, dos fins do homem com os fins do Estado.

O que a humanidade pede, como fundamento de Paz, não são declarações de direitos, nem afirmação de princípios, tantas vezes consagradas nas Constituïções e nas Conferências internacionais.

O que a humanidade pede é o reconhecimento dêsses direitos, a maneira de tornar efetivo o seu exercício, a garantia formal, concreta, de que todos os homens e todos os povos têm direito à vida e aos meios necessários para que a Vida possa por todos ser vivida. 